\title{
Clara Isabel Martínez Cantón: Métrica y poética de Anto- nio Colinas. Sevilla: Rhythmica. Revista Española de Métrica Comparada. Anejo IV, 2011.
}

\section{Juan Ramón Jiménez habló de que}

la poesía, principio y fin de todo, es indefinible. Si se definiera, el definidor sería el dueño de su secreto, el dueño de ella, el verdadero, el único dios posible. Y el secreto de la poesía no lo ha sabido, no lo sabe, no lo sabrá nunca nadie, ni la poesía admite dios alguno, es diosa única de dios, por fortuna para Dios y para los poetas,

idealizando así al arte de escribir poesía y a los poetas mismos cuyas composiciones poéticas invitan a perderse en lo infinito. Todo poema conoce, por tanto, un ritmo y un sentido particulares, capaces de suscitar multitud de sensaciones en aquellos lectores que se acercan a una composición poética para entenderla pero, sobre todo, para sentirla. Si la poesía requiere una sensibilidad especial para su comprensión y la correspondiente emoción que pueda originar, el estudio de cuestiones métricas y poéticas también exige un don particular, tal y como demuestra Clara Isabel Martínez Cantón en su estudio Métrica y poética de Antonio Colinas (2011), un libro indispensable para todos aquellos interesados en la poesía del poeta bañezano -que tiene en su haber premios tan importantes como el Premio de la Crítica, el Premio Nacional de Literatura, el Premio de las Letras de Castilla y León, el Premio Internacional Carlo Betocchi o el Premio de la Academia de Poesía de Castilla y León, entre otros (p. 9)-, así como en la métrica de sus composiciones líricas «como base productora del ritmo poemático y como elemento formal dotado de significación», pues no olvidemos que el ritmo, como dijera José Hierro, «es lo que hace a la poesía persuasiva, y no informativa». 
Es evidente que la poesía se puede estudiar desde perspectivas semánticas, estilísticas, pragmáticas, etc. pero, sin duda, el análisis de la métrica, «un elemento muy olvidado en los estudios críticos de poesía» (p. 9), resulta ser una visión laboriosa y compleja en el intento de acercarse a la poética de un determinado autor. De hecho, en el caso concreto que nos ocupa, «la métrica juega un papel sumamente importante en la obra de Antonio Colinas para quien el aspecto técnico refuerza la musicalidad y el ritmo poemático» (p. 11). Todo estudio métrico requiere, por tanto, el asentamiento de unos férreos presupuestos teóricos y, así, el presente trabajo parte de cuestiones teóricas concretas sobre métrica para aplicarlas a las composiciones poéticas de Colinas. Serán seis los capítulos principales referidos a la explicación de ese arte que se sirve del ritmo, de la estructura, de la medida y de la combinación de los versos, ejemplificando todo ello a través de la poesía y poemarios del poeta leonés.

En primer lugar, Clara Isabel Martínez analiza la sílaba métrica, pues no hemos de olvidar que «la igualdad o proporcionalidad del número de sílabas de cada verso se convierte en español y en la mayoría de las lenguas romances en uno de los elementos rítmicos fundamentales de la poesía» (p. 13). Aparejados a la noción de la sílaba métrica están los conceptos de sinalefa, dialefa o hiato, sinéresis y diéresis que la estudiosa explica con claridad y concisión, junto con el análisis de las peculiaridades que se dan en los versos dependiendo de si terminan en palabra aguda, llana o esdrújula. El siguiente capítulo está dedicado al acento y, en concreto, al «análisis del ritmo acentual en la obra de Antonio Colinas, intentando acercarnos, concretamente, a dos puntos: las tendencias generales en la acentuación de sus versos y el uso de los acentos rítmicos y antirrítmicos» (p. 33) ya que, como se indicó anteriormente, la genialidad del estudio de la profesora Martínez Cantón radica en que cada afirmación que realiza sobre cuestiones métricas viene acompañada con ejemplos concretos que ratifican los postulados teóricos asentados.

En el capítulo cuarto de Métrica y poética de Antonio Colinas, dedicado a la pausa, se habla de la esticomitia y del encabalgamiento en la poesía del mencionado escritor, y de los valores expresivos y efectos semánticos que puede implicar encabalgar un 
verso sobre otro. En realidad, tal y como manifiesta Clara Isabel Martínez, «la pausa actúa como elemento delimitador de grupos melódicos, que pueden formarse por necesidad de respirar o por factores sintácticos, pausas que podemos llamar "naturales", o por factores rítmicos (para delimitar un verso, un hemistiquio, etc.), a estas pausas podremos llamarlas "métricas" o "convencionales”» (p. 45). Asimismo, en este capítulo se defiende que el encabalgamiento, como fenómeno contrario a la esticomitia, «es un recurso estilístico» (p. 49) que «propicia una gama de casos muy amplia en los que se puede percibir en mayor o menor medida el fenómeno» (p. 49). Aplicado a la poesía de Colinas, la estudiosa ha contabilizado "cada uno de los encabalgamientos versales y clasificado según la unidad escindida y según la longitud de la misma en los versos encabalgante y encabalgado» (p. 51), e igualmente ha realizado con otros encabalgamientos mediales, analizando por separado poemas regulares y poemas de verso libre, ofreciendo «datos absolutos y porcentuales» (p. 51) con la pretensión de «llegar a una idea más clara de la incidencia de este recurso en la poesía de Antonio Colinas, así como de su evolución y de la tipología más utilizada» (p. 51). La conclusión a la que llega la autora después de todo es que «el encabalgamiento supone un recurso de gran expresividad, capaz de sugerir muy variados significados. Antonio Colinas se vale de él y lo aprovecha de una manera significativa pero nunca forzada, reservando los tipos más extraños para ocasiones contadas en las que aportan una significación especial» (p. 83).

El capítulo cinco está dedicado a la rima, un «elemento métrico discutido» (p. 85) al poder ser «considerado no como un componente fundamental del verso, sino más bien un elemento dentro de un conjunto de recursos fónicos que se utilizan ocasionalmente en el verso y que refuerzan el ritmo» (p. 85). En el caso concreto de los poemas de Colinas se pueden hablar de rimas sistemáticas a final de verso, o «poemas rimados [...] que constan de una rima a final de verso que se repite en algún orden dentro del poema, y que por ello tiene un papel métrico» (p. 87), y de rimas asistemáticas o «rima suelta [...] muy común en la poesía actual, si bien este tipo de rima no se constituye plenamente como elemento métrico, ya que su función no es 
estructural» (p. 99), diferenciando dentro de ella entre rima asistemática suelta y rima asistemática interna. Asimismo, en este capítulo se esquematizan los diversos tipos de rima según su colocación a final de verso o en el interior de los mismos, según la calidad de la rima que da lugar a la diferenciación entre rima consonante o asonante, según el axis rítmico de las palabras de la rima y según la frecuencia de uso de la rima.

Este completísimo estudio de fundamentos teóricos métricos, focalizado en los poemas de Colinas, se redondea con los capítulos seis y siete dedicados a los tipos de versos más utilizados por el poeta leonés -el endecasílabo, el alejandrino, el verso libre y el verso de arte menor-, pero también sus poemas en prosa incluidos en Jardín de Orfeo (1984-1988); y las estructuras poemáticas más comunes en sus composiciones poéticas, incidiendo en el hecho de que «en la poesía de Antonio Colinas encontramos muy pocos poemas estróficos. [...] Este hecho no es casual, sino que parece responder a una búsqueda de unidad, de cohesión, a la que ayuda de manera visible el uso de la estrofa» (p. 196). En efecto, estructuras poemáticas como el soneto o el romance son escasamente practicadas por Colinas o, en el caso concreto de la silva, el poeta no sigue la concepción clásica de «poema formado por la combinación asimétrica de endecasílabos, o de endecasílabos y heptasílabos, con rima consonante libremente dispuesta, y con la posibilidad de dejar algunos versos sueltos» (p. 201); «sí hace uso, sin embargo, de varias de sus evoluciones que se consideran ya hoy como formas tipificadas de versificación» (p. 201).

El extenso capítulo ocho está dedicado a tratar más específicamente la evolución métrica en la poesía y poemarios de Antonio Colinas como Córdoba adolescente (1963), Junto al lago (1967), Poemas de la tierra y la sangre (1967), Preludios a una noche total (1967-1968), Truenos y flautas en un templo (19681970), Sepulcro en Tarquinia (1970-1974), Astrolabio (19751979), En lo oscuro (1980), La viña salvaje (1972-1980), Noche más allá de la noche (1980-1981), Jardín de Orfeo (1984-1988), La muerte de Armonía (1990), Los silencios de fuego (19881992), Libro de la mansedumbre (1993-1997), Tiempo y abismo (1999-2002) y Desiertos de la luz (2008). Antes de ello, la 
profesora Martínez explica la división que ella ha realizado de las etapas de la trayectoria poética del autor, consciente de que «aunque la clasificación de la literatura por movimientos, etapas, etc. siempre encierra algo de manipulación de la misma, es un criterio de gran utilidad para la organización de un estudio» (p. 204), percatándose de que «la obra de Colinas se presenta como muy ligada a sí misma, lo que hace aún más difícil su organización» (p. 204).

El último capítulo es el dedicado a las conclusiones, al reconocimiento o compendio de las afirmaciones mantenidas a lo largo del libro, focalizando dichas deducciones en una serie de puntos clave como «la utilización en la obra de Antonio Colinas de los componentes del verso» (p. 285) para conseguir un ritmo específico según la sílaba, el acento, la pausa o la rima usados por el poeta leonés; o los «metros hegemónicos y combinaciones de versos en la poesía de Antonio Colinas» (p. 289), hablando del endecasílabo, del alejandrino, del verso libre, del verso de arte menor o del poema en prosa para, seguidamente, tratar el tema de «la relativa importancia de las estructuras poemáticas clásicas en la poesía de Antonio Colinas» (p. 293), y de la evolución y renovación de sus poemarios. En realidad, la profesora Martínez Cantón considera que, tras el largo camino explicativo recorrido, el análisis de la métrica de Colinas «se revela así como una herramienta utilísima en varios aspectos: comprender los elementos que influyen de manera más decisiva en la creación de un ritmo, observar el grado de tradición y renovación del autor respecto a su época, y analizar la evolución de la obra del poeta» (p. 296).

No obstante, el estudio no termina con estas conclusiones sino que, antes de la bibliografía, Clara Isabel Martínez añade un par de anexos en los que se incluyen una entrevista sobre métrica realizada en octubre de 2010 al propio Antonio Colinas que resulta tremendamente atractiva y clarificadora de lo que el poeta piensa o las razones por las que sigue una métrica concreta o si estaría dispuesto a utilizar formas métricas provenientes de otros países como el haiku japonés, o por qué su escasa práctica del soneto, pues no hay nada como acudir a la fuente concreta, en este caso, al escritor en cuestión, para ratificar las creencias e investigaciones realizadas; mientras que el segundo anexo hace somera referencia 
a la publicación de la Obra poética completa de Colinas en 2011 en la editorial Siruela, afirmando que «la importancia de esta nueva edición de poesía del autor es crucial, ya que demuestra, como él mismo afirma, que el círculo aún no se ha cerrado, que su poesía aún tiene mucho que ofrecer, y se abrirá a nuevos caminos en los que seguro no faltarán nuevas innovaciones métricas» (p. 315) porque la poesía del ayer, del hoy y del mañana siempre tratará de ofrecer, como manifestara Octavio Paz,

conocimiento, salvación, poder y abandono. Operación capaz de cambiar al mundo, la actividad poética es revolucionaria por naturaleza; ejercicio espiritual, es un método de liberación interior. La poesía revela este mundo; crea otro. Pan de los elegidos; alimento maldito. Aísla; une. Invitación al viaje; regreso a la tierra natal [...] en su seno se resuelven todos los conflictos objetivos y el hombre adquiere al fin conciencia de ser algo más que tránsito.

NuRia SÁnChez ViLladangos Universidad de León 